ИЗВЕСТИЯ АКАДЕМИИ НАУК ЭСТОНСКОП ССР. ТОМ 32

ХИМИЯ. 1983, Nㅛ 1

удК 661.632 .12

Э. ААСАМЯЭ, М. ВЕИДЕРМА

\title{
ВЛИЯНИЕ ДОБАВКИ КАРБАМИДА НА АЗОТНОКИСЛОТНО-СУЛЬФАТНУЮ ПЕРЕРАБОТКУ ПРИРОДНЫХ ФОСФАТОВ
}

При исследовании азотнокислотной переработки тоолсеского фосфорита было установлено, что существенный недостаток этого процесса - интенсивное выделение оксидов азота [']. Показано, что потери $\mathrm{HNO}_{3}$ в газовой фазе можно уменьшить предварительным обжигом фосфорита или введением в стадию разложения определенных добавок, преимущественно карбамида $\left.{ }^{1-6}\right]$.

Взаимодействие карбамида с оксидами азота выражается следующими реакциями $\left[{ }^{3,5}\right]$ :

$$
\begin{aligned}
& \mathrm{NO}_{2}+\mathrm{NO}+2 \mathrm{CO}\left(\mathrm{NH}_{2}\right)_{2} \cdot \mathrm{HNO}_{3}=2 \mathrm{CO}_{2}+2 \mathrm{~N}_{2}+2 \mathrm{NH}_{4} \mathrm{NO}_{3}+\mathrm{H}_{2} \mathrm{O}, \\
& 2 \mathrm{HNO}_{2}+\mathrm{CO}\left(\mathrm{NH}_{2}\right)_{2}=2 \mathrm{~N}_{2}+\mathrm{CO}_{2}+3 \mathrm{H}_{2} \mathrm{O}, \\
& 3 \mathrm{NO}_{2}+2 \mathrm{CO}\left(\mathrm{NH}_{2}\right)_{2}=3,5 \mathrm{~N}_{2}+2 \mathrm{CO}_{2}+4 \mathrm{H}_{2} \mathrm{O}, \\
& 3 \mathrm{NO}_{2}+4 \mathrm{CO}\left(\mathrm{NH}_{2}\right)_{2}+4 \mathrm{HNO}_{3}=3,5 \mathrm{~N}_{2}+4 \mathrm{CO}_{2}+4 \mathrm{NH}_{4} \mathrm{NO}_{3}+2 \mathrm{H}_{2} \mathrm{O} .
\end{aligned}
$$

Целью настоящего исследования было определение количества карбамида, необходимого для ликвидации потерь $\mathrm{HNO}_{3}$ при переработке природных фосфатов азотнокислотно-сульфатными методами, а также установление влияния карбамида на другие показатели процесса (степень извлечения $\mathrm{P}_{2} \mathrm{O}_{5}$ и $\mathrm{Fe}_{2} \mathrm{O}_{3}$, скорость фильтрации фосфогипса и др.) В качестве фосфатного сырья использовали образцы флотационного концентрата эстонского фосфорита (месторождения Тоолсе и Маарду), а для сравнения - также образцы хибинского и ковдорского апатита. Из характеристики фосфатного сырья (табл. 1) следует, что образцы фосфорита отличаются более высоким содержанием нерастворимого остатка, соединений железа и серы, чем образцы апатита. Образец маардуского фосфорита содержит больше пирита, чем проба тоолсеского фосфорита, а отношение общ. $\mathrm{Fe}_{2} \mathrm{O}_{3}: \mathrm{P}_{2} \mathrm{O}_{5}$ в обеих пробах одинаково.

$\mathrm{B}$ предварительных опытах определяли потери $\mathrm{HNO}_{3}$ при азотнокислотном разложении фосфатного сырья без добавления сульфат-иона и карбамида. В основных сериях экспериментов изучали два варианта процесса азотнокислотной переработки фосфатов с введением сульфатиона и варьированием добавки карбамида: 1) азотно-сернокислотносульфатное и 2) азотнокислотно-сульфатное разложение. Процесс изучали до стадии получения продукционного фильтрата и сухого промытого осадка (фосфогипса).

\section{Методика}

Суммарное количество $\mathrm{H}^{+}$-иона, необходимое для разложения фосфатов, и количество сульфат-иона - для осаждения иона кальция, принимались равными стехиометрической норме, рассчитанненбепе २еодержанию $\mathrm{CaO}$ 


\section{Характеристика образцов фосфатного сырья}

\begin{tabular}{|c|c|c|c|c|}
\hline \multirow[b]{2}{*}{ Показатели, \% } & \multicolumn{2}{|c|}{ Апатит } & \multicolumn{2}{|c|}{ Фосфорит } \\
\hline & хибинский & ковдорский & $\begin{array}{l}\text { тоолсе- } \\
\text { ский }\end{array}$ & $\begin{array}{l}\text { маарду- } \\
\text { ский }\end{array}$ \\
\hline $\begin{aligned} & \text { Содержание } \mathrm{P}_{2} \mathrm{O}_{5} \\
& \mathrm{CaO} \\
& \mathrm{MgO}\end{aligned}$ & $\begin{array}{l}39,2 \\
52,0 \\
\text { не опр. }\end{array}$ & $\begin{array}{l}37,8 \\
52,7 \\
2,85\end{array}$ & $\begin{array}{l}27,4 \\
39,5 \\
1,15\end{array}$ & $\begin{array}{r}28,8 \\
41,2 \\
1,0\end{array}$ \\
\hline $\begin{array}{l}\text { Железо в пересчёте на } \mathrm{Fe}_{2} \mathrm{O}_{3} \\
\text { общее } \\
\text { пиритное * }\end{array}$ & $\begin{array}{c}0,37 \\
\text { не опр. }\end{array}$ & $\begin{array}{c}0,22 \\
\text { не опр. }\end{array}$ & $\begin{array}{l}2,55 \\
0,93\end{array}$ & $\begin{array}{l}2,85 \\
2,49\end{array}$ \\
\hline $\begin{array}{l}\text { Сера в пересчёте на } \mathrm{SO}_{3} \\
\text { общая } \\
\text { пиритная } \\
\mathrm{CO}_{2} \\
\mathrm{~F}\end{array}$ & $\begin{array}{c}0,15 \\
\text { не опр. } \\
0,17 \\
3,28\end{array}$ & $\begin{array}{l}0,20 \\
\text { не опр. } \\
2,60 \\
1,06\end{array}$ & $\begin{array}{l}2,42 \\
1,86 \\
3,05 \\
2,58\end{array}$ & $\begin{array}{l}5,48 \\
4,97 \\
3,39 \\
2,73\end{array}$ \\
\hline Нерастворимый остаток & 1,17 & 0,74 & 18,3 & 14,5 \\
\hline $\begin{array}{l}\text { Отношение } \\
\mathrm{CaO}: \mathrm{P}_{2} \mathrm{O}_{5} \\
\mathrm{MgO}: \mathrm{P}_{2} \mathrm{O}_{5} \\
\text { общее } \mathrm{Fe}_{2} \mathrm{O}_{3}: \mathrm{P}_{2} \mathrm{O}_{5} \\
\text { пиритное } \mathrm{Fe}_{2} \mathrm{O}_{3}: \mathrm{P}_{2} \mathrm{O}_{5}\end{array}$ & $\begin{array}{l}133 \\
\text { не опр. } \\
0,9 \\
\text { не опр. }\end{array}$ & $\begin{array}{l}139 \\
7,5 \\
0,6 \\
\text { не опр. }\end{array}$ & $\begin{array}{r}144 \\
4,2 \\
9,3 \\
3,4\end{array}$ & $\begin{array}{r}143 \\
3,5 \\
9,9 \\
8,6\end{array}$ \\
\hline $\begin{array}{l}\text { Остаток на сите } \\
+180 \text { мкм }\end{array}$ & 8,0 & 10,7 & 22,4 & 20,8 \\
\hline
\end{tabular}

* Пиритное железо в пересчёте на $\mathrm{Fe}_{2} \mathrm{O}_{3}$, рассчитанное по формуле:

$$
\text { пиритное } \mathrm{Fe}_{2} \mathrm{O}_{3}=\frac{\text { (общая } \left.\mathrm{SO}_{3}-\text { сульфатная } \mathrm{SO}_{3}\right) \cdot 159,7}{4 \cdot 80} \text {. }
$$

в фосфатном сырье. Количество отдельных реагентов составляло для I варианта по $50 \% \mathrm{HNO}_{3}, \mathrm{H}_{2} \mathrm{SO}_{4}$ и $\left(\mathrm{NH}_{4}\right)_{2} \mathrm{SO}_{4}$, для II варианта - по $100 \%$ $\mathrm{HNO}_{3}$ и $\left(\mathrm{NH}_{4}\right)_{2} \mathrm{SO}_{4}$ стехиометрической нормы. Сульфат аммония и карбамид растворяли в смеси серной и азотной кислот, разбавленной водой до достижения в конечной пульпе отношения Ж:Т $=3: 1$ (при переработке хибинского апатита $4: 1$ ). Количество карбамида составляло $0-70$ г на 1000 г фосфатного сырья.

Для разложения фосфатов применяли стеклянный герметичный реактор с пропеллерной мешалкой. При дозировании фосфоритов пеногасителем использовали $1 \%$-ный раствор сукцинола. Дозировали в течение $1-2$ мин, перемешивали пульпу 1 ч, температура пульпы составляла $75^{\circ} \mathrm{C}$. Выделяющиеся из реактора газы абсорбировали раствором $\mathrm{H}_{2} \mathrm{O}_{2}$. По окончании перемешивания пульпу отфильтровывали, осадок промывали тремя порциями подогретой воды и высушивали при $75-80^{\circ}$. Анализ фосфатного сырья и продуктов разложения проводили по методам, изложенным в $[7,8]$.

\section{Результаты экспериментов}

По данным предварительных опытов (табл. 2), потери $\mathrm{HNO}_{3}$ в опытах без добавки сульфат-иона и карбамида весьма существенно различаются в зависимости от вида фосфатного сырья и от количества использованной $\mathrm{HNO}_{3}$. При разложении хибинского апатита потери были ничтожными $(0,2-0,4$ г на 1000 г апатита), при переработке ковдорского апатита - в 2,5-3,5 раза больше. Потери достигали максимального 
Потери $\mathrm{HNO}_{3}$ при разложении фосфатного сырья азотной кислотой

\begin{tabular}{|c|c|c|c|c|c|}
\hline \multirow[b]{3}{*}{ Фосфорит } & \multirow[b]{3}{*}{ или апатит } & \multicolumn{2}{|c|}{ Норма $\mathrm{HNO}_{3} 50 \%$} & \multicolumn{2}{|c|}{ Норма $\mathrm{HNO}_{3} 100 \%$} \\
\hline & & \multicolumn{4}{|c|}{ Потери $\mathrm{HNO}_{3}$ в газовой фазе, $\mathrm{r}$} \\
\hline & & $\begin{array}{l}\text { на } 1000 \text { г } \\
\text { фосфата }\end{array}$ & $\begin{array}{c}\% \text { от вве- } \\
\text { денной } \\
\mathrm{HNO}_{3}\end{array}$ & $\begin{array}{l}\text { на } 1000 \mathrm{r} \\
\text { фосфата }\end{array}$ & $\begin{array}{c}\% \text { от вве- } \\
\text { денной } \\
\mathrm{HNO}_{3}\end{array}$ \\
\hline $\begin{array}{l}\text { Хибинский } \\
\text { Ковдорский } \\
\text { Тоолсеский } \\
\text { Маардуский }\end{array}$ & & $\begin{array}{c}0,23 \\
0,79 \\
15,1 \\
52,2\end{array}$ & $\begin{array}{c}0,039 \\
0,133 \\
3,40 \\
11,2\end{array}$ & $\begin{array}{c}0,40 \\
0,94 \\
31,6 \\
74,0\end{array}$ & $\begin{array}{l}0,034 \\
0,078 \\
3,53 \\
8,0\end{array}$ \\
\hline
\end{tabular}

Таблица 3

Разложение природных фосфатов смесью $\mathrm{HNO}_{3}+\mathrm{H}_{2} \mathrm{SO}_{4}+\left(\mathrm{NH}_{4}\right)_{2} \mathrm{SO}_{4}$

\begin{tabular}{|c|c|c|c|c|c|c|c|c|c|c|}
\hline \multirow{4}{*}{ Показатели } & \multicolumn{3}{|c|}{ Апатит } & \multirow{2}{*}{\multicolumn{2}{|c|}{ тоолсескиі }} & \multicolumn{3}{|c|}{ Фосфорит } & \multirow{2}{*}{\multicolumn{2}{|c|}{ дуский }} \\
\hline & $\begin{array}{l}\text { хи- } \\
\text { бин- } \\
\text { ский }\end{array}$ & \multicolumn{2}{|c|}{$\begin{array}{l}\text { ковдор- } \\
\text { ский }\end{array}$} & & & & 0,0 & маард & & \\
\hline & \multicolumn{10}{|c|}{ Добавка карбамида на $1000 \mathrm{r}$ фосфата, г } \\
\hline & 0 & 0 & $4 \mid$ & 0 & 10 & 20 & 0 & 10 & 15 & 20 \\
\hline $\begin{array}{c}\text { Потери } \mathrm{HNO}_{3} \text { на } \\
1000 \mathrm{r} \text { фосфата, }\end{array}$ & & & & & & & & & & des? \\
\hline $\mathrm{r}-\mathrm{l}=$ & 0 & 0,3 & 0,1 & 5,8 & 2,8 & 0,2 & 18,8 & 17,5 & 15,8 & 0,3 \\
\hline $\begin{array}{r}\text { Содержание } \mathrm{P}_{2} \mathrm{O}_{5} \text { в } \\
\text { жидкой фазе, \% }\end{array}$ & 6,4 & 7,3 & 7,5 & 5,9 & 5,8 & 6,0 & 6,8 & 7,1 & 7,0 & 7,5 \\
\hline $\begin{array}{l}\text { Отношение } \\
\mathrm{Fe}_{2} \mathrm{O}_{3}: \mathrm{P}_{2} \mathrm{O}_{5} \\
\text { жидкой фазе, \% }\end{array}$ & 0,6 & 0,7 & 0,7 & 9,9 & 8,9 & 5,8 & 6,8 & 8,5 & 8,4 & 1,8 \\
\hline $\begin{array}{c}\text { Коэффициент из- } \\
\text { влечения в жид- } \\
\text { кую фазу }(\%):\end{array}$ & & & & & & & & & fict & \\
\hline $\begin{array}{l}\mathrm{P}_{2} \mathrm{O}_{5} \\
\mathrm{Fe}_{2} \mathrm{O}_{3}\end{array}$ & $\begin{array}{l}92 \\
60\end{array}$ & $\begin{array}{l}86 \\
88\end{array}$ & $\begin{array}{l}87 \\
88\end{array}$ & $\begin{array}{l}83 \\
81\end{array}$ & $\begin{array}{l}81 \\
76\end{array}$ & $\begin{array}{l}83 \\
55\end{array}$ & $\begin{array}{l}85 \\
70\end{array}$ & $\begin{array}{l}90 \\
74\end{array}$ & $\begin{array}{l}89 \\
71\end{array}$ & $\begin{array}{l}94 \\
16\end{array}$ \\
\hline $\begin{array}{c}\text { Расход } 1 \% \text {-ного } \\
\text { сукщинола на на } \\
1000 \text { г фосфата, }\end{array}$ & & & & & & & & & 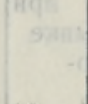 & \\
\hline r & 0 & 0 & 0 & 24 & 4 & 0 & 75 & 32 & 10 & 0 \\
\hline $\begin{array}{l}\text { Расход } \mathrm{H}^{+} \text {-иона на } \\
1000 \mathrm{r} \text { извлечен- } \\
\text { ной } \mathrm{P}_{2} \mathrm{O}_{5}, \mathrm{r}\end{array}$ & 29,8 & 38,6 & 37,6 & 35,2 & 38,4 & 38,6 & 34,9 & 35,5 & 36,8 & 34,7 \\
\hline $\begin{array}{l}\text { Скорость фильтра- } \\
\text { ции при промыв- } \\
\text { ке фосфогипса, } \\
\mathrm{M}^{3} / \mathrm{M}^{2} \cdot 4\end{array}$ & 0,84 & 0,80 & 0,61 & 0,51 & 0,72 & 0,60 & 0,73 & 0,62 & 0,78 & yexp \\
\hline
\end{tabular}

значения при разложении маардуского фосфорита (74 г на 1000 г фосфатного сырья или $8 \%$ от количества введенной кислоты), а в опытах с тоолсеским фосфоритом они менее значительны (до $3,5 \%$ ).

Основные серии опытов (табл. 3 и 4) показали, что при использовании сульфат-иона в процессе азотнокислотного разложения эстонского 
Разложенйе природных фосфатов смесью $\mathrm{HNO}_{3}+\left(\mathrm{NH}_{4}\right)_{2} \mathrm{SO}_{4}$

\begin{tabular}{|c|c|c|c|c|c|c|c|c|c|c|c|}
\hline \multirow{4}{*}{$\begin{array}{c}\text { Показа- } \\
\text { тели }\end{array}$} & \multicolumn{3}{|c|}{ Апатит } & \multicolumn{8}{|c|}{ Фосфорит } \\
\hline & $\begin{array}{l}\text { хи- } \\
\text { бин- } \\
\text { ский }\end{array}$ & \multicolumn{2}{|c|}{$\begin{array}{l}\text { ковдор- } \\
\text { ский }\end{array}$} & \multicolumn{3}{|c|}{ тоолсеский } & \multicolumn{5}{|c|}{ маардуский } \\
\hline & \multicolumn{11}{|c|}{ Добавка карбамида на 1000 г фосфата, г } \\
\hline & 0 & 0 & 4 & 0 & 10 & 20 & 0 & 10 & 20 & 40 & 70 \\
\hline $\begin{array}{l}\text { Потери } \\
\mathrm{HNO}_{3} \\
\text { на } 1000 \mathrm{r} \\
\text { фосфата, r }\end{array}$ & 0,3 & 0,8 & 0,5 & 4,3 & 2,2 & 0,7 & 14,4 & 10,5 & 7,3 & 3,6 & 0,6 \\
\hline $\begin{array}{c}\text { Содержание } \\
\mathrm{P}_{2} \mathrm{O}_{5} \text { в } \\
\text { жидкой } \\
\text { фазе, \% }\end{array}$ & 6,8 & 8,1 & 8,2 & 6,5 & 6,2 & 6,2 & 7,4 & 7,4 & 7,0 & 7,2 & 7,4 \\
\hline $\begin{array}{l}\text { Отношение } \\
\mathrm{Fe}_{2} \mathrm{O}_{3}: \mathrm{P}_{2} \mathrm{O}_{5} \\
\text { в жидкой } \\
\text { фазе, } \%\end{array}$ & 0,6 & 0,6 & 0,6 & 9,1 & 9,0 & 8,6 & 9,1 & 9,1 & 9,0 & 8,1 & 2,8 \\
\hline $\begin{array}{l}\text { Коэффи- } \\
\text { циент из- } \\
\text { влечения в } \\
\text { жидкую } \\
\text { фазу, \%: }\end{array}$ & & & & & & & & & & & \\
\hline $\begin{array}{l}\mathrm{P}_{2} \mathrm{O}_{5} \\
\mathrm{Fe}_{2} \mathrm{O}_{3}\end{array}$ & $\begin{array}{l}95 \\
68\end{array}$ & $\begin{array}{l}91 \\
92\end{array}$ & $\begin{array}{l}93 \\
91\end{array}$ & $\begin{array}{l}86 \\
84\end{array}$ & $\begin{array}{l}84 \\
82\end{array}$ & $\begin{array}{l}83 \\
77\end{array}$ & $\begin{array}{l}92 \\
84\end{array}$ & $\begin{array}{l}92 \\
84\end{array}$ & $\begin{array}{l}91 \\
80\end{array}$ & $\begin{array}{l}89 \\
68\end{array}$ & $\begin{array}{l}92 \\
24\end{array}$ \\
\hline $\begin{array}{c}\text { Расход } 1 \%- \\
\text { ного сук- } \\
\text { цинола на } \\
1000 \text { г фос- } \\
\text { фата, г }\end{array}$ & 0 & 0 & 0 & 26 & 25 & 23 & 10 & 0 & 0 & 0 & 0 \\
\hline $\begin{array}{c}\text { Расход } \mathrm{H}^{+-} \\
\text {иона на } \\
1000 \text { г из- } \\
\text { влеченной } \\
\mathrm{P}_{2} \mathrm{O}_{5}, \mathrm{r}\end{array}$ & 29,8 & 37,4 & 37,5 & 35,8 & 36,1 & 38,7 & 32,9 & 34,0 & 35,5 & 39,0 & 35,4 \\
\hline $\begin{array}{l}\text { Скорость } \\
\text { фильтра- } \\
\text { ции при } \\
\text { промывке } \\
\text { фосфо- } \\
\text { гипса, } \\
\text { м }^{3} / \mathrm{M}^{2} \cdot \text { ч }\end{array}$ & 1,31 & 0,86 & 0,64 & 0,69 & 0,42 & 0,68 & 0,56 & 0,61 & 0,77 & 0,67 & 0,69 \\
\hline
\end{tabular}

фосфорита потери $\mathrm{HNO}_{3}$ в газовой фазе снижаются в $4-7$ раз, но остаются еще сравнительно высокими $(4-6$ г для тоолсеского и $14-19$ г для маардуского фосфорита*). Добавление карбамида в количестве 20 г на 1000 г тоолсеского фосфорита обеспечивало снижение потерь до $0,2-0,7$ г, что сходно с потерями при переработке апатитов. Однако, при разложении маардуского фосфорита смесью $\mathrm{HNO}_{3}$ и $\left(\mathrm{NH}_{4}\right)_{2} \mathrm{SO}_{4}$ для получения аналогичного результата потребовалось добавить 70 г карбамида. Снижение потерь $\mathrm{HNO}_{3}$ с увеличением количества карбамида проходило в общем плавно (рис. 1), за исключением опыта азотносернокислотно-сульфатного разложения маардуского фосфорита. Во

\footnotetext{
* Здесь и далее потери $\mathrm{HNO}_{3}$ выражаются в граммах на 1000 г фосфатного сырья.
} 


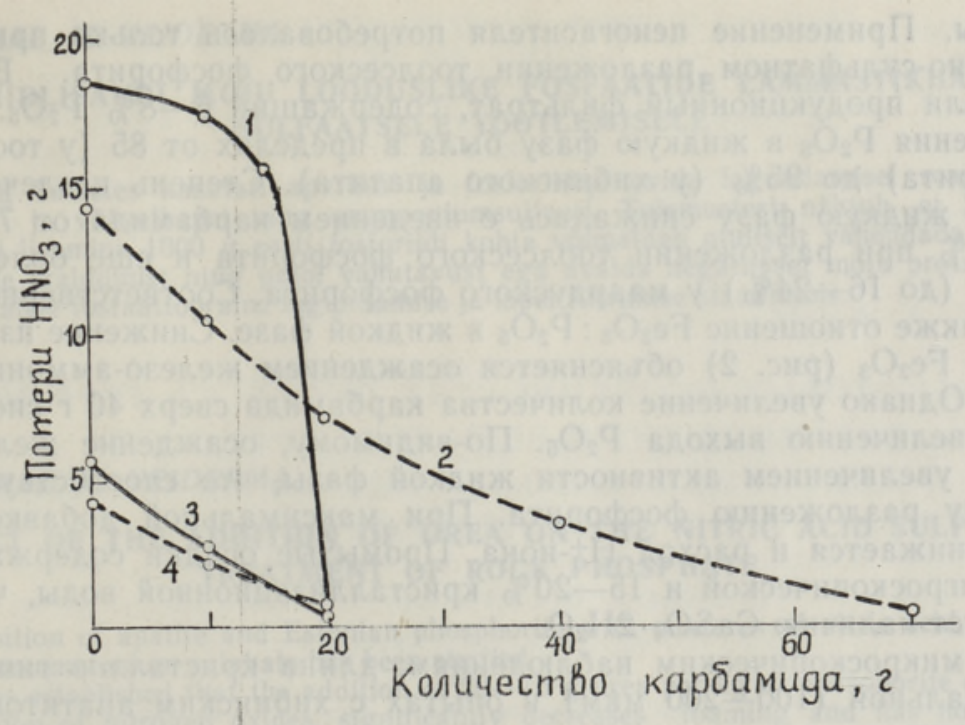

Рис. 1. Зависимость потерь $\mathrm{HNO}_{3}$ от добавки карбамида (в граммах на 1000 г фосфорита) при переработке эстонского фосфорита смесью $\mathrm{HNO}_{3}+\mathrm{H}_{2} \mathrm{SO}_{4}+\left(\mathrm{NH}_{4}\right)_{2} \mathrm{SO}_{4}$ (сплошные кривые) и смесью $\mathrm{HNO}_{3}+\left(\mathrm{NH}_{4}\right)_{2} \mathrm{SO}_{4}$ (пунктирные кривые). 1, 2 - маардуский фосфорит; 3,4 - тоолсеский фосфорит.

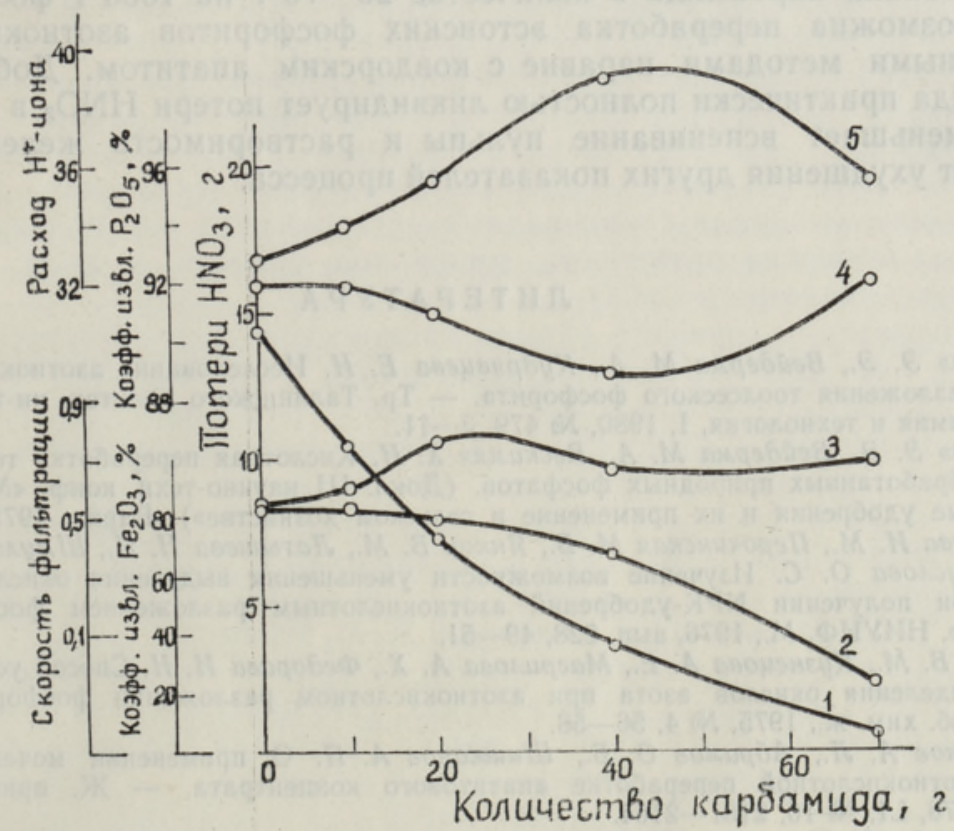

Рис. 2. Зависимость показателей процесса разложения маардуского фосфорита смесью $\mathrm{HNO}_{3}+\left(\mathrm{NH}_{4}\right)_{2} \mathrm{SO}_{4}$ от добавки карбамида (в граммах на $1000 \mathrm{r}$ фосфорита). 1 - потери $\mathrm{HNO}_{3}$ на 1000 г фосфорита, г; 2 - коэффициент извлечения $\mathrm{Fe}_{2} \mathrm{O}_{3}, \%$; 3 - скорость фильтрации, $\mathrm{m}^{3} / \mathrm{M}^{2} \cdot 4 ; 4-$ коэффициент извлечения $\mathrm{P}_{2} \mathrm{O}_{5}, \% ; 5$ - расход $\mathrm{H}^{+}$-иона на 1000 г извлеченной $\mathrm{P}_{2} \mathrm{O}_{5}, \mathrm{r}$.

всех опытах расход карбамида выше, чем соответствующий вышеприведенным реакциям его взаимодействия с оксидами азота.

Добавление карбамида обычно вызывает уменьшение вспенивания 
пульпы. Применение пеногасителя потребовалось только при азотнокислотно-сульфатном разложении тоолсеского фосфорита. В опытах получали продукционный фильтрат, содержащий $6-8 \% \quad \mathrm{P}_{2} \mathrm{O}_{5}$. Степень извлечения $\mathrm{P}_{2} \mathrm{O}_{5}$ в жидкую фазу была в пределах от 85 (у тоолсеского фосфорита) до $95 \%$ (у хибинского апатита). Степень извлечения железа в жидкую фазу снижалась с введением карбамида от 70-84 до $55-77 \%$ при разложении тоолсеского фосфорита и еще более значительно (до 16-24\%) у маардуского фосфорита. Соответственно снижалось также отношение $\mathrm{Fe}_{2} \mathrm{O}_{3}: \mathrm{P}_{2} \mathrm{O}_{5}$ в жидкой фазе. Снижение извлечения $\mathrm{P}_{2} \mathrm{O}_{5}$ и $\mathrm{Fe}_{2} \mathrm{O}_{3}$ (рис. 2) объясняется осаждением железо-аммонийфосфатов [9]. Однако увеличение количества карбамида сверх 40 г способствовало увеличению выхода $\mathrm{P}_{2} \mathrm{O}_{5}$. По-видимому, осаждение железа связано с увеличением активности жидкой фазы, что способствует более полному разложению фосфорита. При максимальной добавке карбамида снижается и расход $\mathrm{H}^{+}$-иона. Промытые, осадки содержали 38 $56 \%$ гигроскопической и $15-20 \%$ кристаллизационной воды, что соответствует наличию $\mathrm{CaSO}_{4} \cdot 2 \mathrm{H}_{2} \mathrm{O}$.

По микроскопическим наблюдениям, длина кристаллов гипса была максимальной (100-200 мкм) в опытах с хибинским апатитом, а при использовании других видов сырья составляла в среднем 40-60 мкм. В соответствии с размером кристаллов изменялась также скорость фильтрации, которая в опытах с фосфоритами была в 1,5-2 раза меньше, чем при переработке хибинского апатита.

Таким образом, из проведенного исследования следует, что при использовании карбамида в количестве 20-70 г на 1000 г фосфатного сырья возможна переработка эстонских фосфоритов азотнокислотносульфатными методами наравне с ковдорским апатитом. Добавление карбамида практически полностью ликвидирует потери $\mathrm{HNO}_{3}$ в газовую фазу, уменьшает вспенивание пульпы и растворимость железа и не вызывает ухудшения других показателей процесса.

\section{ЛИТ Е РА Т У Р А}

1. Аасамяэ Э. Э., Вейдерма М. А., Кудрявцева Е. Н. Исследованне азотнокислотного разложения тоолсеского фосфорита. - Тр. Таллинского политех. ин-та. Неорг. химия и технология, I, 1980, № 479, 3-11.

2. Аасамяэ Э. Э., Вейдерма М. А., Вескимяэ Х. И. Кислотная переработка термически обработанных природных фосфатов. (Докл. III научно-техн. конф. «Минеральные удобрения и их применение в сельском хозяйстве»). Варна, 1975, 3-7.

3. Мальцева Н. М., Перочинская М. Б., Янкин В. М., Латышева Н. П., Шмульян Е. К., Суслова О. С. Изучение возможности уменьшения выделения окислов азота при получении NPK-удобрений азотнокнслотным разложением фосфата. Тр. НИУИФ. М., 1976, вып. 228, 49-51.

4. Беглов В. М., Кузнецова А. Е., Магрилова А. Х., Федорова Н. Н. Способ устранения выделения окислов азота при азотнокислотном разложении фосфоритов. Узб. хим. ж., 1975, № 4, 56-58.

5. Гольдинов А. Л., Абрамов О. Б., Шииканов А. П. О применении мочевины при азотнокислотной переработке апатитового концентрата. - Ж. прикл. хим., 1978, LI, № 10, 2161-2164.

6. Rosenzweig, $M$. Urea cuts $\mathrm{NO}_{x}$ in Norway. - Chem. Eng., 1975, 44D-44F.

7. Методы анализа фосфатного сырья, фосфорных и комплексных удобрений, кормовых фосфатов. М., 1975.

8. Пылдме М. Э., Пылдме Ю. Х., Борисова Г. С. Определение фосфата усовершенствованным методом дифференциальной фотоколориметрии. - Тр. Таллинского политех. ин-та, 1976, № 397, 59-64.

9. Марголис Ф. Г., Кармышов В. Ф., Глазова Т. В., Франчук Н. П., Портнова Н. Л. Изучение части изотермы в системе $\mathrm{Fe}_{2} \mathrm{O}_{3}-\mathrm{P}_{2} \mathrm{O}_{5}-\mathrm{N}_{2} \mathrm{O}_{5}-\left(\mathrm{NH}_{4}\right)_{2} \mathrm{O}-\mathrm{H}_{2} \mathrm{O}$ при $55^{\circ} \mathrm{C}$. - Тр. НИУИФ. М., 1973, вып. 221, 46-55. 


\section{KARBAMIIDLISANDI MOJU LOODUSLIKE FOSFAATIDE LAMMASTIKHAPPELIS- SULFAATSELE TOOTLEMISELE}

Kirjeldatud katsetes kasutati apatiidi- ja fosforiidiproovide lagundamisel reagentidena lämmastik- ja väävelhapet ning ammooniumsulfaati. Tulemustest nähtub, et $20-70 \mathrm{~g}$ karbamiidi lisamine $1000 \mathrm{~g}$ eesti fosforiidi kohta võimaldab oluliselt vähendada lämmastikoksiidide eraldumist ning pulbi vahutavust ega avalda negatiivset mõju protsessi teistele näitajatele fosfaattooraine lagundamise ja kipsi filtrimise staadiumis.

\section{E. AASAMÄE, M. VEIDERMA}

\section{EFFECT OF THE ADDITION OF UREA ON THE NITRIC ACID SULPHATE TREATMENT OF ROCK PHOSPHATE}

Decomposition of apatite and Estonian phosphorite with mixtures of nitric acid, sulphuric acid and/or ammonium sulphate has been studied.

It was established that the addition of $20-70 \mathrm{~g}$ urea per $\mathrm{kg}$ of phosphorite eliminates the emission of nitrogen oxides, significantly decreases foaming and has no negative effect on the other indicators of the process during the decomposition, filtration and washing. 